\title{
THE EFFECT OF OXYTOCIN AND ADRENALINE ON THE SEMEN OUTPUT OF RAMS
}

\author{
T. W. KNIGHT \\ Department of Animal Science and Production, Institute of Agriculture, \\ University of Western Australia, Nedlands, Western Australia 6009, Australia
}

(Received 19th October 1973)

Summary. An intravenous injection of 10 i.u. oxytocin into rams $10 \mathrm{~min}$ before ejaculation increased the number of spermatozoa per ejaculate by $45 \%$. The optimum dose was between 5 and 10 i.u. oxytocin and the optimum interval between the injection of oxytocin and ejaculation was 5 to $10 \mathrm{~min}$. The increase in the number of spermatozoa per ejaculate was accompanied by increases in semen volume, and/or sperm concentration. The increase in the semen volume and total fructose per ejaculate suggested that oxytocin stimulated the accessory sex glands. Adrenaline injections had no effect on the output of semen.

\section{INTRODUCTION}

In flocks of sheep in which large numbers of spermatozoa must be collected from a few rams over a short period for artificial insemination (A.I.), a substantial increase in the output of spermatozoa per ejaculate per ram would be an advantage. Milovanov, Bereznev \& Gorohov (1962) increased the number of spermatozoa per ejaculate from bulls used in an A.I. centre by intravenous injection of 3 to 18 i.u. oxytocin just before ejaculation. The optimum dose for the bull was 6 i.u. oxytocin but the ejaculate had to be collected within 5 min of the injection. In rams, oxytocin has also been found to increase the number of spermatozoa per ejaculate (Knight \& Lindsay, 1970) but the dose of oxytocin and the conditions for a maximum response have not been determined. The work by Ewy, Bielański \& Zapletal (1963) on the output of semen from the cannulated ductus deferens of a ram following oxytocin injection suggests that the optimum time for collection would be 10 to $40 \mathrm{~min}$ after the injection of oxytocin.

The contractions of the epididymis and ductus deferens which cause the emission of semen during ejaculation are stimulated by catecholamines released from the sympathetic nerve endings associated with the muscular layers (Cross \& Glover, 1958; Sjöstrand, 1965). It might, therefore, be expected that exogenous adrenaline would also increase the output of spermatozoa.

Two experiments were designed to determine the dose of oxytocin and the interval between the injection of oxytocin and ejaculation which would produce the maximum output of semen from rams. A third experiment determined the maximum increase in the output of spermatozoa following injections 
of oxytocin and the effect of injecting oxytocin before one of the two ejaculations. The possibility of increasing the output of semen with injections of adrenaline was considered in a fourth experiment. To test the hypothesis that the difference between rams in the output of semen may be due to differences in the endogenous release of oxytocin or adrenaline, the experiments were performed on a group of rams with a high number of spermatozoa per ejaculate and a second group of rams with a low number of spermatozoa per ejaculate.

\section{MATERIALS AND METHODS}

Four collections of semen were made from each of eight rams using an artificial vagina. On the basis of the mean number of spermatozoa per ejaculate, the rams were allocated to a high-yielding group (Group 1) or a low-yielding group (Group 2). Each group consisted of four rams.

Two semen collections, $90 \mathrm{~min}$ apart, were made from each ram every 3rd day. The volume of the semen was measured and the concentration of spermatozoa in the semen was determined colorimetrically, using a Gilford 2000 spectrophotometer by the method of Knight (1972). The concentration of fructose in the semen was measured by the method of Mann (1948), which was adapted for use on an autoanalyser (Knight, 1972).

All the injections were given into the jugular vein. The oxytocin used was Pitocin (Parke Davis). The adrenaline was made up each day by dissolving $1 \mathrm{mg}$ adrenaline (BDH) in $10 \mathrm{ml}$ sterilized distilled water, to which a small quantity of ascorbic acid was added to prevent oxidation of the adrenaline.

The experiments were a series of paired $4 \times 4$ Latin squares on the two groups of rams so that each ram received each treatment once during the experimental period. Four consecutive experiments were performed on the rams.

Experiment 1. This experiment compared the effect of different doses of oxytocin on the output of semen. The maximum interval between the injection of oxytocin and collection of the ejaculate was $1 \frac{1}{2}$ min.

The treatments were: (1) no oxytocin $-1 \mathrm{ml}$ sterilized saline; (2) 5 i.u. oxytocin; (3) 10 i.u. oxytocin; (4) 15 i.u. oxytocin.

Experiment 2. This experiment compared the effect of collecting the ejaculate at different intervals after the injection of 10 i.u. oxytocin.

The intervals of time were: (1) a maximum of $1 \frac{1}{2} \mathrm{~min}$; (2) 5 min after the injection; (3) 10 min after the injection; (4) 20 min after the injection.

Experiment 3. This experiment compared the response to 10 i.u. oxytocin injected intravenously $10 \mathrm{~min}$ before each ejaculation, and before either the first or the second ejaculation. The experiment was duplicated to increase the precision.

The treatments were: (1) no oxytocin-1 $\mathrm{ml}$ sterilized saline; (2) 10 i.u. oxytocin before the first and the second ejaculation; (3) 10 i.u. oxytocin before the first but not the second ejaculation; (4) 10 i.u. oxytocin before the second but not the first ejaculation.

Experiment 4. This experiment determined the effect of adrenaline on the output of semen. The maximum time from the injection to the collection of the ejaculate was $1 \frac{1}{2} \mathrm{~min}$. 
The treatments were: (1) no adrenaline-1 ml sterilized saline; (2) $25 \mu \mathrm{g}$ adrenaline; (3) $50 \mu \mathrm{g}$ adrenaline; (4) $100 \mu \mathrm{g}$ adrenaline.

The results were analysed by split plot analysis of variance. Interactions with a mean square less than the error mean square were pooled with the error term. Orthogonal comparisons were made between the treatments.

\section{RESULTS}

\section{General}

The rams in Group 1 maintained a significantly larger number of spermatozoa per ejaculate, volume of semen and total fructose per ejaculate than the rams in Group 2 throughout the four experiments (Tables 1, 2, 4 and 6). While the sperm concentration was significantly higher for the rams in Group 1 than for those in Group 2 in the first three experiments, there was no difference in the fourth experiment. The relationship between the two groups of rams with respect to the concentration of fructose in the semen varied during the four experiments (Tables 1, 2, 4 and 6).

\section{Experiment 1}

While oxytocin injections produced a mean increase of $22.9 \%$ in the number of spermatozoa per ejaculate $(P<0.05)$, there were no significant differences between the three doses of oxytocin (Table 1). This increase in the number of spermatozoa per ejaculate was associated with a mean increase of $11.8 \%$ in the sperm concentration $(P<0.05)$ and a mean increase of $10.5 \%$ in the volume of semen (N.S.). The response was similar in the two groups of rams.

Table 1. The means of the semen characteristics of rams in Exp. 1 for different doses of oxytocin and different groups

\begin{tabular}{|c|c|c|c|c|c|c|}
\hline \multirow{2}{*}{ Semen characteristic } & \multicolumn{4}{|c|}{ i.u. Oxytocin } & \multicolumn{2}{|c|}{ Groups } \\
\hline & 0 & 5 & 10 & 15 & 1 & 2 \\
\hline $\begin{array}{l}\text { Semen volume }(\mathrm{ml}) \\
\text { Sperm conc. }\left(\times 10^{9} / \mathrm{ml}\right) \\
\text { No. of spermatozoa/ejaculate }\end{array}$ & $\begin{array}{l}0.63 \\
3 \cdot 83^{\text {a1 }}\end{array}$ & $\begin{array}{l}0.72 \\
4.06^{\mathrm{b} 1}\end{array}$ & $\begin{array}{l}0 \cdot 69 \\
4 \cdot 44^{b 1}\end{array}$ & $\begin{array}{l}0 \cdot 67 \\
4 \cdot 33^{b 1}\end{array}$ & $\begin{array}{l}0 \cdot 89^{\mathrm{a} 3} \\
4 \cdot 90^{\mathrm{a} 3}\end{array}$ & $\begin{array}{l}0 \cdot 46^{\mathrm{b3}} \\
3 \cdot 44^{\mathrm{b3}}\end{array}$ \\
\hline $\begin{array}{l}\left(\times 10^{9}\right) \\
\text { Fructose conc. in semen }\end{array}$ & $2 \cdot 57^{\text {a } 1}$ & $3 \cdot 12^{b 1}$ & $3 \cdot 30^{\mathrm{b} 1}$ & $3.06^{\mathbf{b} 1}$ & $4 \cdot 44^{\mathrm{a} 3}$ & $1 \cdot 58^{\mathrm{b} 3}$ \\
\hline $\begin{array}{l}(\mathrm{mg} / \mathrm{ml}) \\
\text { Total fructose/ejaculate }(\mathrm{mg})\end{array}$ & $\begin{array}{l}4 \cdot 38^{\mathrm{a} 2} \\
2 \cdot 66\end{array}$ & $\begin{array}{l}3 \cdot 90^{\mathrm{b} 2} \\
2 \cdot 93\end{array}$ & $\begin{array}{l}3 \cdot 54^{\text {b2 }} \\
2 \cdot 43\end{array}$ & $\begin{array}{l}3 \cdot 81^{\mathbf{b} 2} \\
2 \cdot 52\end{array}$ & $\begin{array}{l}3 \cdot 80 \\
3 \cdot 36^{\mathrm{a} 3}\end{array}$ & $\begin{array}{l}4 \cdot 02 \\
1.91^{b 3}\end{array}$ \\
\hline
\end{tabular}

Means with the same alphabetic superscripts are not significantly different. The superscript numbers designate the level of significance. $1=P<0.05 ; 2=P<0.01 ; 3=P<0.001$.

Although the concentration of fructose in the semen was significantly less $(P<0 \cdot 01)$ after oxytocin injections, there was no effect on the total fructose per ejaculate (Table 1).

\section{Experiment 2}

When the interval between the injection of oxytocin and ejaculation was greater than $1 \frac{1}{2} \mathrm{~min}$, there were mean increases of $35.2 \%$ in the number of 
Table 2. The means of the semen characteristics of rams in Exp. 2 for different time intervals from oxytocin injection to ejaculation and different groups

\begin{tabular}{|c|c|c|c|c|c|c|}
\hline \multirow{2}{*}{ Semen characteristics } & \multicolumn{4}{|c|}{$\begin{array}{l}\text { Interval from intravenous injection of } 10 \text { i.u. } \\
\text { oxytocin to ejaculation (min) }\end{array}$} & \multicolumn{2}{|c|}{ Groups } \\
\hline & $1-1 \frac{1}{2}$ & 5 & 10 & 20 & 1 & 2 \\
\hline $\begin{array}{l}\text { Semen volume }(\mathrm{ml}) \\
\text { Sperm conc. }\left(\times 10^{9} / \mathrm{ml}\right) \\
\text { No of spermatozoa/ejaculate }\end{array}$ & $\begin{array}{l}0 \cdot 64^{\mathrm{a1}} \\
3 \cdot 71\end{array}$ & $\begin{array}{l}0.73^{b 1} \\
3 \cdot 88\end{array}$ & $\begin{array}{l}0 \cdot 79^{b 1} \\
3 \cdot 82\end{array}$ & $\begin{array}{l}0 \cdot 76^{\mathbf{b 1}} \\
3 \cdot 80\end{array}$ & $\begin{array}{l}0.98^{\mathbf{a}} \\
4 \cdot 65^{\mathrm{a3}}\end{array}$ & $\begin{array}{l}0.49^{\mathrm{b} 3} \\
2 \cdot 96^{\mathrm{b3}}\end{array}$ \\
\hline $\begin{array}{l}\left(\times 10^{9}\right) \\
\text { Fructose conc, in semen }\end{array}$ & $2 \cdot 37^{\mathrm{a} 2}$ & $3 \cdot 10^{\mathrm{b2}}$ & $3 \cdot 24^{b 2}$ & $3 \cdot 27^{\mathbf{b} 2}$ & $4 \cdot 58^{\mathrm{a3}}$ & $1.41^{\mathrm{b3}}$ \\
\hline $\begin{array}{l}\text { (mg/ml) } \\
\text { Total fructose/ejaculate (mg) }\end{array}$ & $\begin{array}{l}3 \cdot 63 \\
2 \cdot 55\end{array}$ & $\begin{array}{l}3 \cdot 38 \\
2 \cdot 41\end{array}$ & $\begin{array}{l}3 \cdot 57 \\
2 \cdot 67\end{array}$ & $\begin{array}{l}4 \cdot 04 \\
2 \cdot 90\end{array}$ & $\begin{array}{l}3 \cdot 38^{\mathrm{a} 1} \\
3 \cdot 23^{\mathrm{a} 3}\end{array}$ & $\begin{array}{l}3 \cdot 95^{\mathrm{b} 1} \\
2 \cdot 03^{\mathrm{b3}}\end{array}$ \\
\hline
\end{tabular}

Means with the same alphabetic superscripts are not significantly different. The superscript numbers designate the level of significance. $1=P<0.05 ; 2=P<0.01 ; 3=P<0.001$.

spermatozoa per ejaculate $(P<0.01), 18.8 \%$ in the volume of semen $(P<0.05)$ and $3.3 \%$ (N.S.) in the sperm concentration (Table 2). There was no significant effect of increasing the interval between the injection of oxytocin to ejaculation from $5 \mathrm{~min}$ to 10 or $20 \mathrm{~min}$. The response was almost totally accounted for by the rams in Group 1 but the difference in the response of the two groups of rams was only significant $(P<0.01)$ for the volume of semen (Table 3$)$.

There were no effects of the time from oxytocin injection to semen collection on total fructose per ejaculate or concentration of fructose in the semen (Table 2).

\section{Experiment 3}

The injection of 10 i.u. oxytocin $10 \mathrm{~min}$ before the collection of an ejaculate significantly increased $(P<0.001)$ the number of spermatozoa per ejaculate compared with the rams not receiving oxytocin (Table 4). The number of spermatozoa per ejaculate was $45.5 \%$ greater with oxytocin injections before each of the two ejaculations but only $27.5 \%$ greater with a single injection of oxytocin before either the first or the second ejaculation. Two injections of

Table 3. The means of the number of spermatozoa per ejaculate, volume of semen and sperm concentration for the group $\times$ treatment interactions for rams in Exp. 2

\begin{tabular}{|c|c|c|c|c|c|}
\hline \multirow[t]{2}{*}{ Semen characteristics } & \multirow[t]{2}{*}{ Groups } & \multicolumn{4}{|c|}{$\begin{array}{l}\text { Interval from intravenous injection of } 10 i . u \\
\text { oxytocin to ejaculation (min) }\end{array}$} \\
\hline & & $1-1 \frac{1}{2}$ & 5 & 10 & 20 \\
\hline $\begin{array}{l}\text { No. of spermatozoa/ } \\
\text { ejaculate }\left(\times 10^{9}\right)\end{array}$ & $\begin{array}{l}1 \\
2\end{array}$ & $\begin{array}{l}3 \cdot 40 \\
1 \cdot 34\end{array}$ & $\begin{array}{l}4 \cdot 82 \\
1 \cdot 38\end{array}$ & $\begin{array}{l}4.92 \\
1.56\end{array}$ & $\begin{array}{l}5 \cdot 17 \\
1 \cdot 37\end{array}$ \\
\hline Semen volume $(\mathrm{mI})$ & $\begin{array}{l}1 \\
2\end{array}$ & $\begin{array}{l}0 \cdot 76 \\
0.53\end{array}$ & $\begin{array}{l}1 \cdot 03 \\
0 \cdot 44\end{array}$ & $\begin{array}{l}1.03 \\
0.55\end{array}$ & $\begin{array}{l}1 \cdot 10 \\
0 \cdot 43\end{array}$ \\
\hline Sperm conc. $\left(\times 10^{9} / \mathrm{ml}\right)$ & $\begin{array}{l}1 \\
2\end{array}$ & $\begin{array}{l}4 \cdot 50 \\
2 \cdot 92\end{array}$ & $\begin{array}{l}4 \cdot 67 \\
3 \cdot 09\end{array}$ & $\begin{array}{l}4 \cdot 79 \\
2 \cdot 86\end{array}$ & $\begin{array}{l}4 \cdot 65 \\
2 \cdot 96\end{array}$ \\
\hline
\end{tabular}


Table 4. The means of the semen characteristics of rams in Exp. 3 for the oxytocin treatment and different groups

\begin{tabular}{|c|c|c|c|c|c|c|}
\hline \multirow{2}{*}{ Semen characteristics } & \multicolumn{4}{|c|}{10 i.u. Oxytocin before ejaculation } & \multicolumn{2}{|c|}{ Groups } \\
\hline & 0 & $1+2$ & 1 & 2 & 1 & 2 \\
\hline \multirow{3}{*}{$\begin{array}{l}\text { Semen volume }(\mathrm{ml}) \\
\text { Sperm conc. }\left(\times 10^{9} / \mathrm{ml}\right) \\
\text { No. of spermatozoa/ } \\
\quad \text { ejaculate }\left(\times 10^{9}\right) \\
\text { Fructose conc. in semen } \\
\quad \text { (mg/ml) } \\
\text { Total fructose/ejaculate }(\mathrm{mg})\end{array}$} & $\begin{array}{l}0.58^{\mathrm{a}^{2}} \\
3 \cdot 80^{2}\end{array}$ & $\begin{array}{l}0.77^{\mathrm{b} 2} \\
4.02\end{array}$ & $\begin{array}{l}0.70^{\mathrm{b} 2} \\
3.91\end{array}$ & $\begin{array}{l}0.70^{\mathrm{b} 2} \\
3 \cdot 82\end{array}$ & $\begin{array}{l}0.84^{\mathrm{a} 3} \\
4.33^{\mathrm{a3}}\end{array}$ & $\begin{array}{l}0.54^{\mathrm{b3}} \\
3.44^{\mathrm{b3}}\end{array}$ \\
\hline & $2 \cdot 23^{\mathrm{a3}}$ & $3 \cdot 24^{\mathrm{b2}}$ & $2 \cdot 80^{\mathrm{c} 2}$ & $2 \cdot 88^{\mathrm{c} 2}$ & $3 \cdot 68^{\mathrm{a3}}$ & $1.90^{\mathrm{b3}}$ \\
\hline & $\begin{array}{l}3 \cdot 69 \\
2 \cdot 11^{\text {a1 }}\end{array}$ & $\begin{array}{l}3.77 \\
3.02^{\mathrm{bi}}\end{array}$ & $\begin{array}{l}3 \cdot 65 \\
2 \cdot 57^{\mathrm{b} 1}\end{array}$ & $\begin{array}{l}3 \cdot 52 \\
2 \cdot 41^{\mathrm{b1}}\end{array}$ & $\begin{array}{l}3 \cdot 83^{21} \\
3 \cdot 15^{\mathrm{a3}}\end{array}$ & $\begin{array}{l}3.47^{\text {b1 }} \\
1.91^{\text {b3 }}\end{array}$ \\
\hline
\end{tabular}

Means with the same alphabetic superscripts are not significantly different. The superscript numbers designate the level of significance. $1=P<0.05 ; 2=P<0.01 ; 3=P<0.001$.

Table 5. The means of the number of spermatozoa per ejaculate, volume of semen and sperm concentration for the group treatment interactions of rams in Exp. 3

\begin{tabular}{l|c|cccc}
\hline \multirow{2}{*}{ Semen characteristics } & \multirow{3}{*}{ Groups } & \multicolumn{4}{|c}{10 i.u. Oxytocin before ejaculation } \\
\cline { 3 - 6 } & & 0 & $1+2$ & 1 & 2 \\
\hline No. of spermatozoa per & 1 & $2 \cdot 84$ & 4.55 & 3.47 & 3.84 \\
ejaculate $\left(\times 10^{9}\right)$ & 2 & 1.61 & 1.93 & $2 \cdot 13$ & 1.92 \\
Semen volume $(\mathrm{ml})$ & 1 & 0.69 & 0.97 & 0.79 & 0.87 \\
& 2 & 0.47 & 0.54 & 0.61 & 0.53 \\
Sperm conc. $\left(\times 10^{9} / \mathrm{ml}\right)$ & 1 & 4.18 & 4.59 & 4.28 & 4.29 \\
& 2 & 3.43 & 3.44 & 3.55 & 3.36 \\
\hline
\end{tabular}

Table 6. The means of the semen characteristics of rams in Exp. 4 for different doses of adrenaline and different groups

\begin{tabular}{|c|c|c|c|c|c|c|}
\hline \multirow{2}{*}{ Semen characteristics } & \multicolumn{4}{|c|}{ Adrenaline $(\mu g)$} & \multicolumn{2}{|c|}{ Groups } \\
\hline & 0 & 25 & 50 & 100 & 1 & 2 \\
\hline $\begin{array}{l}\text { Semen volume }(\mathrm{mI}) \\
\text { Sperm conc. }\left(\times 10^{9} / \mathrm{ml}\right) \\
\text { No. of spermatozoa }\end{array}$ & $\begin{array}{l}0.76 \\
3.51\end{array}$ & $\begin{array}{l}0 \cdot 68 \\
3.56\end{array}$ & $\begin{array}{l}0.71 \\
3 \cdot 43\end{array}$ & $\begin{array}{l}0 \cdot 69 \\
3 \cdot 70\end{array}$ & $\begin{array}{l}0 \cdot 84^{\mathbf{a 3}} \\
3 \cdot 56\end{array}$ & $\begin{array}{l}0 \cdot 53^{\text {b3 }} \\
3 \cdot 54\end{array}$ \\
\hline $\begin{array}{l}\text { ejaculate }\left(\times 10^{9}\right) \\
\text { Fructose conc. in semen }\end{array}$ & $2 \cdot 67$ & $2 \cdot 42$ & $2 \cdot 48$ & $2 \cdot 53$ & $2 \cdot 97^{ \pm 2}$ & $2 \cdot 07^{\mathrm{b} 2}$ \\
\hline $\begin{array}{l}(\mathrm{mg} / \mathrm{ml}) \\
\text { Total fructose/ejaculate (mg) }\end{array}$ & $\begin{array}{l}4 \cdot 80 \\
3 \cdot 85\end{array}$ & $\begin{array}{l}4 \cdot 70 \\
3 \cdot 36\end{array}$ & $\begin{array}{l}4 \cdot 97 \\
3 \cdot 63\end{array}$ & $\begin{array}{l}4 \cdot 41 \\
3 \cdot 26\end{array}$ & $\begin{array}{l}5 \cdot 69^{\mathrm{a3}} \\
4 \cdot 82^{\mathrm{a3}}\end{array}$ & $\begin{array}{l}3 \cdot 75^{\text {b3 }} \\
2 \cdot 23^{\text {b3 }}\end{array}$ \\
\hline
\end{tabular}

Means with the same alphabetic superscripts are not significantly different. The superscript numbers designate the level of significance. $2=P<0.01 ; 3=P<0.001$. 
oxytocin were more effective than one $(P<0.01)$, but there was no difference in the effectiveness of an injection before the first or the second ejaculation.

The volume of semen increased by $33 \%$ when oxytocin was injected before each ejaculation and $20 \%$ when oxytocin was injected before either the first or the second ejaculation (Table 4). Although these increases in the volume of semen were significant $(P<0 \cdot 01)$, the difference between the responses to one or two injections of oxytocin was not significant. The $3 \%$ increase in the concentration of spermatozoa with injections of oxytocin was not significant.

While the injection of oxytocin increased the number of spermatozoa per ejaculate and the volume of semen in both groups of rams, the response was larger in Group 1 than in Group 2 and two injections of oxytocin were better than one injection in Group 1, but not in Group 2 (Table 5). These differences in the response between two groups of rams only reached significance $(P<0.001)$ for the number of spermatozoa per ejaculate.

Total fructose per ejaculate was increased $(P<0.05)$ by the injection of oxytocin, but there was no significant effect on the concentration of fructose in the semen (Table 4).

\section{Experiment 4}

The injection of adrenaline had no significant effect on any of the parameters measured (Table 6).

\section{DISGUSSION}

The results of Exp. 1 indicated that the dose of oxytocin which produced the maximum number of spermatozoa per ejaculate was between 5 and 10 i.u. oxytocin or 0.09 to $0.18 \mathrm{i}$.u. oxytocin $/ \mathrm{kg}$ body weight. The method of collection of semen does not seem to be important since Knight \& Lindsay (1970) found that when using an electroejaculator, the optimum dose of oxytocin was also between 5 and 10 i.u. oxytocin. Similarly, the optimum dose of oxytocin in the bull was 6 i.u. (Milovanov et al., 1962) and Kihlström \& Melin (1963) found that the optimum response to oxytocin in the rabbit was obtained with an intravenous dose of $0 \cdot 15$ i.u. oxytocin $/ \mathrm{kg}$ body weight.

The number of spermatozoa per ejaculate increased as the interval between the injection of oxytocin and ejaculation increased from $1 \frac{1}{2} \mathrm{~min}$ to $20 \mathrm{~min}$. The optimum interval between the injection of oxytocin and ejaculation would appear to be 5 to $10 \mathrm{~min}$. This contrasts with the bull for which ejaculates must be collected within $5 \mathrm{~min}$ of an intravenous injection of oxytocin (Milovanov et al., 1962). When the interval between ejaculations was $90 \mathrm{~min}$, there was no carry-over effect of oxytocin from the first to the second ejaculation and the injection of oxytocin was equally effective before either the first or the second ejaculation.

The intravenous injection of 10 i.u. oxytocin $10 \mathrm{~min}$ before each of two ejaculations increased the number of spermatozoa per ejaculate from $2.23 \times 10^{9}$ to $3.24 \times 10^{9}$, or approximately by $45 \%$. Generally, an increase of this magnitude would not be large enough to warrant the cost and effort involved in injecting the rams with oxytocin when collecting semen for A.I. 
Following oxytocin, the increases in the number of spermatozoa per ejaculate were the result of increases in both the volume of semen and/or the sperm concentration. In Exp. 1, the major effect of oxytocin was to increase the concentration of spermatozoa with a resulting decrease in the concentration of fructose in the semen. By contrast, the major effect of oxytocin in Exp. 3 was to increase the volume of semen. This difference in the response to oxytocin may be associated with the different intervals between oxytocin injection and ejaculation in the two experiments. Increasing the interval between oxytocin injection and ejaculation in Exp. 2 increased the volume of semen while producing only a small change in the sperm concentration per ejaculate.

In Exp. 3, the increase both in the volume of semen and in the total fructose per ejaculate suggests that oxytocin had stimulated either the formation of seminal plasma or its expulsion from the seminal vesicles. Kihlström \& Melin (1963) and Fjellström, Kihlström \& Melin (1968), working with rabbits, also obtained indirect evidence that oxytocin stimulated the accessory sex glands. Oxytocin has been shown to stimulate contractions of the epididymides in the ram (Knight, 1972) and the epididymides and ductus deferens of the bull and rabbit (Milovanov et al., 1962; Bereznev, 1964; Melin, 1970) but there is no direct evidence that oxytocin will stimulate contractions or secretion in the male accessory sex glands. Cross \& Glover (1958) and Melin (1970) found that oxytocin did not increase the muscular activity of the seminal vesicles of the rabbit.

Intravenous adrenaline had no effect on the output of semen when the ejaculate was collected immediately after the injection. Although VanDemark \& Baker (1953) found that intravenous injection of adrenaline into bulls decreased the volume of semen and sperm concentration, they did not state the length of the interval between injection and collection. The lack of response to exogenous adrenaline is possibly because adequate amounts of endogenous adrenaline are already released near the organs.

The rams with the high output of semen responded more regularly to the injection of oxytocin and the responses were larger than for those with the low output of semen. The large difference in the output of semen by the two groups of rams cannot be explained either by a lack of the release of endogenous oxytocin or by adrenaline.

\section{ACKNOWLEDGMENTS}

I wish to thank Dr D. R. Lindsay for advice and Mr T. Johnson for technical assistance. Financial support was provided by the Australian Meat Research Committee.

\section{REFERENGES}

Bereznev, A. P. (1964) The role of oxytocin in the process of ejaculation in bulls. Proc. 5th Int. Congr. Anim. Reprod., Toronto, 6, 101.

Gross, B. A. \& Glover, T. D. (1958) The hypothalamus and seminal emission. F. Endocr. 16, 385.

EwY, Z., BiELAŃsKI, W. \& ZAPLETAL, Z. (1963) Influence of oxytocin on sperm transport in the ductus deferens of the ram. Bull. Acad. pol. Sci. Cl. II Sér. Sci. biol. 11, 145.

Fjeliström, D., Kinlström, J. E. \& Melin, P. (1968) The effect of synthetic oxytocin upon seminal characteristics and sexual behaviour in male rabbits. F. Reprod. Fert. 17, 207. 
Kinlström, J. E. \& Melin, P. (1963) Influence of oxytocin upon some seminal factors in the rabbit. Acta physiol. scand. 59, 363.

KNIGHT, T. W. (1972) A study of factors which affect the potential fertility of the ram. Ph.D. thesis, University of Western Australia.

KNIGHT, T. W. \& LiNDSAY, D. R. (1970) Short- and long-term effects of oxytocin on quality and quantity of semen from rams. J. Reprod. Fert. $21,523$.

ManN, T. (1948) Fructose content and fructolysis in semen. Practical application in the evaluation of semen quality. F. agric. Sci., Camb. 38, 321.

MeLin, P. (1970) Effects in vivo of neurophypophysial hormone on the contractile activity of accessory sex organs in male rabbits. 7. Reprod. Fert. 22, 283.

Milovanov, V. K., Bereznev, A. P. \& Gorohov, L. N. (1962) The effect of oxytocin on the reproductive system of male livestock. Anim. Breed. Abstr. 32, 101.

Sjöstrand, N. O. (1965) The adrenergic innervation of the vas deferens and the accessory male genital glands. Acta physiol. scand. 65, Suppl. 257.

VanDemark, N. L. \& Baker, F. M. (1953) The effect of daily injections of epinephrine on semen production of bulls. F. Anim. Sci. 12, 956. 